\title{
Pattern of comorbidities in school-aged children with cerebral palsy in Cross River State, Nigeria
}

Roseline E. Duke ${ }^{1,2^{*}}$, Chimaeze Torty ${ }^{3}$, Uche Okorie$^{2}$, Min J. Kim ${ }^{1}$ Nnena Eneli ${ }^{4}$, Ukam Edadi ${ }^{5}$, Kathryn Burton ${ }^{6}$, Cally Tann ${ }^{7}$ and Richard Bowman ${ }^{1}$

\begin{abstract}
Background: To describe the pattern of comorbidities in school-aged children with cerebral palsy (CP) and to identify which, if any, were associated with poor school attendance.

A cross-sectional study, using the key informant methodology, between December 2017 and July 2018 was conducted in Cross River State, Nigeria. Assessments, confirmation of CP and identification of systemic comorbidities using standard tools and questionnaires were performed. Children confirmed to have CP between the ages 4 to 15 years were included.
\end{abstract}

Results: Three hundred and eighty-eight children were confirmed to have CP, 59\% males. The mean age was 9.2 years \pm SD 4.0; $28 \%$ were non-ambulatory (gross motor function classification system (GMFCS) level IV-V) and spastic CP was seen in 70\%. Comorbidities included Speech impairment 85\%, feeding difficulties $86 \%$, and swallowing difficulties $77 \%$, learning difficulties $88 \%$, abnormal behaviour 62\%, visual acuity impairment 54\%, objective perceptual visual disorders $46 \%$, communication difficulties $45 \%$, epilepsy $35 \%$, hearing impairment $12 \%$ and malnutrition 51\%. Learning difficulties (OR 10.1, $p<0.001$; Cl: 3.6-28.1), visual acuity impairment (OR 2.8, $p=$ $0.002 ; \mathrm{Cl}: 1.5-5.3)$, epilepsy (OR 2.3, $p=0.009$; Cl:1.2-4.3) manual ability classification scale 4-5 (OR 4.7,p=0.049; Cl: 1.0-22.2) and CP severity (GMFCS V-VI) OR $6.9 p=0.002, \mathrm{Cl}$ : 2.0-24.0.) were seen as increasing the likelihood of poor school attendance.

Conclusion: Comorbidities were common, and some were associated with limited school attendance. A multidisciplinary tailored approach to care, with application of available therapeutic interventions for comorbidities is suggested. This may be useful in reducing barriers to school attendance.

Keywords: Cerebral palsy, Comorbidity, School attendance, Children

\footnotetext{
*Correspondence: dr.roseineduek@gmail.com; dr.roselineduke@gmail.com 'London School of Hygiene \& Tropical Medicine, International Centre for Eye Health, London, UK

${ }^{2}$ Department of Ophthalmology, University of Calabar Teaching Hospital, Calabar Children's Eye Centre, Calabar, Cross River State, Nigeria

Full list of author information is available at the end of the article
}

(c) The Author(s). 2021 Open Access This article is licensed under a Creative Commons Attribution 4.0 International License, which permits use, sharing, adaptation, distribution and reproduction in any medium or format, as long as you give appropriate credit to the original author(s) and the source, provide a link to the Creative Commons licence, and indicate if changes were made. The images or other third party material in this article are included in the article's Creative Commons licence, unless indicated otherwise in a credit line to the material. If material is not included in the article's Creative Commons licence and your intended use is not permitted by statutory regulation or exceeds the permitted use, you will need to obtain permission directly from the copyright holder. To view a copy of this licence, visit http://creativecommons.org/licenses/by/4.0/ The Creative Commons Public Domain Dedication waiver (http://creativecommons.org/publicdomain/zero/1.0/) applies to the data made available in this article, unless otherwise stated in a credit line to the data. 


\section{Introduction}

Cerebral palsy (CP) is a leading cause of childhood disability across the world with significant impact on function and development [1]. The definition of $\mathrm{CP}$ highlights frequent association with disorders of sensation, perception, cognition, communication, behaviour, with epilepsy and secondary musculoskeletal problems [2]. Co-morbidities affect the overall health and quality of life in children by determining their participation in most aspects of life including schooling [3]. Secondary conditions (e.g. joint contractures and malnutrition) occur and are preventable. Children with more severe levels of gross motor dysfunction present with comorbidity more frequently $[4,5]$. It is estimated that the majority of children with disabilities in Africa do not go to school at all [6], and of the 72 million primary aged children worldwide that are out of school, one third have disabilities [7]. Few reports describe school attendance and educational attainment in children with CP in Low and Middle Income Countries (LMIC).

Children with $\mathrm{CP}$ and disability in general face barriers and challenges to education [6]. Barriers to attending school are commonly described through the 'social model' of disability, that is about the way the society responds to children with disability. The common ones are physical, social and financial [8]. This 'social model' of disability differs from the 'medical model' which sees people with disabilities as having a problem that needs to be managed, changed and/or adapted to circumstances [9].

Co-morbidities may contribute to these barriers. Little evidence exists as to whether and which comorbidities are significant barriers to participation in schooling. Identification of these comorbidities may be important to attain effective individualized support measures for education.

In Nigeria, there are strong regional disparities in education and socioeconomic indices, with the southern region of the country (where Cross River State is situated) performing better in indices, including of health, education and the millennium development goals [10]. In the general population of children in Nigeria, the gross enrolment rate in elementary school is $68.3 \%$, gross enrolment rate in lower secondary is $54.4 \%$ and upper secondary $68.9 \%$ [11] With regards to malnutrition, $37 \%$ of children are stunted and in addition $18 \%$ of children suffer from wasting while $29 \%$ of children are underweight [12].

The aim of this study was to describe the comorbidities seen in children with $\mathrm{CP}$ in this community based Nigerian population, and to identify which comorbidities were associated with poor school attendance.

\section{Methods}

\section{Study setting/context}

A population based cross sectional study was conducted in Cross River State (CRS) in Nigeria between December 2017 and July 2018 and has been reported in other articles [13-15].

Primary and secondary education enrolment is compulsory; however, it is paid for by the government for children in the primary school, while the government subsidizes the examination fees for the secondary education. Located in every village is a primary school and in every local government area there is a state government secondary school and a mission secondary school. Enrolment into kindergarten is from 3 years old. Secondary school education is divided into junior secondary and senior secondary schools [16]. There are three government special education schools in the state for deaf, mute and visually impaired children.

\section{Sample size}

Existing data from this world region suggest a population prevalence of $\mathrm{CP}$ of 2.9 per 1000 children and about the same estimate for associated comorbidities [17-19]. Considering the population size for the total number of children aged 4-15 years in Cross River State as $1.1 \mathrm{M}$ [20], a $10 \%$ non-response rate, a sample size of 370 would be sufficient to estimate a prevalence of 2.9/1000 (i.e. $p=0.29 \%$ ) and associated comorbidities [17] with a level of precision of $\pm 0.58 \%$.

\section{Sampling strategy}

In the absence of a cerebral palsy registry, the key informant methodology (KIM) was selected as the most cost effective sampling strategy to identify children with $\mathrm{CP}$ and other disabilities in our circumstances. Several researches have validated this method [21-24]. The key informant methodology (KIM) was chosen, recognising its effectiveness for identifying physical impairment compared to household survey in LMIC [25]. The methodology used is referred to in other articles [13-15].

Identified and referred children were then assessed first of all by a paediatric neurologist in the primary health centre to determine if they met the inclusion criteria for CP. Families were provided with appropriate advice, information and counselling, referral services and intervention where appropriate. CP was defined according to history and neurological examination in line with international criteria [26]. Gross Motor Function Classification Scale (GMFCS) was used to describe the severity of CP of gross motor impairment. These levels were categorized into ambulatory (Levels I-III) and nonambulatory (Levels IV-V) [27]. Validated existing questionnaires and tools were used such as the strength difficulties questionnaire, the manual ability classifications 
system and the communication function classification system.

The inclusion criteria included, children aged between 4 and 15 years of age at their last birthday, who were confirmed to have $\mathrm{CP}$ from history and clinical assessment by a paediatric neurologist [28]. Exclusion criteria included children who had other motor disorders apart from $\mathrm{CP}$ and children outside the age criteria and those that refused to participate in the study.

\section{Comorbidity case ascertainment}

Comorbid conditions were confirmed by history, clinical and standardized evaluations. Comorbidities investigated included: epilepsy, hearing impairment, feeding difficulties, swallowing difficulties, visual acuity impairment, objective perceptual visual disorders, abnormal behaviour, learning difficulty, speech impairment, communication difficulties and malnutrition.

The Lea symbols cut-off point for screening preschool children of 0.8 was used as score for normal visual acuity and $>0.8$ were considered to have visual acuity impairment [29]. Objective perceptual visual impairment was ascertained by a battery of tests [14].

Hearing impairment was assessed using three-level voice test (for children able to participate) and was present when a child failed to respond to mid-level spoken voice in either ear. Learning difficulty was assessed, by clinical history, assessment and behavioural observation [30, 31]. The Communication Function Classification Scale (CFCS) assessed the full activity of communication in five levels between a familiar person and the child [32]. We referred to children as having communication impairment if CFCS was level 4-5. Speech impairment were defined as inability to create or form speech sounds [33]. Epilepsy was diagnosed on a history of having two unprovoked seizures $>24 \mathrm{~h}$ apart at any time from 1 month of age to assessment [34]. Feeding difficulties was based on the reported ability of the child to chew food and the need for food to be cut up or mashed. Swallowing difficulties was defined as choking and coughing on food or drink based on parental report [35]. The manual ability classification system (MACS) [36], categorized as $1-3$ and $4-5$ as severe manual ability impairment. The strength and difficulties questionnaire(SDQ) [37], which is an emotional and behavioural screening questionnaire, was used through parent interview to describe any behavioural abnormality, emotional and conduct problems, hyperactivity, peer problems and prosocial behaviours [38]. Behaviour disorder was defined using the total difficulties score from the Strength and Difficulties Questionnaire. Malnutrition was classified using the Centre for Disease Control (CDC) growth chart (for ages 2-19 years) [39, 40], and comprised of underweight or wasting, stunting and overweight. Severe acute malnutrition was defined as weight for height at least $3 \mathrm{SD}$ below the reference median or mid- upper arm circumference less than $11.5 \mathrm{~cm}$ for children less than 5 years [41].

Participation in mainstream schooling was recorded alongside whether children were at expected levels within the school programme by parent's report. Dropout in school was defined as the percentage of students failing to complete a particular school year or school program.

\section{Statistical analysis}

Statistical analyses were performed using Stata 15 (Stata Corp LP, College Station, TX). Descriptive statistics were reported using means, standard deviations, medians, interquartile ranges, frequencies and percentages. Comparisons between categorical variables were performed using a chi-square test and logistic regression.

Comorbidity score was calculated by summation of the frequencies of the following comorbidities: feeding, swallowing, hearing, speech, learning, visual acuity impairments and objective perceptual visual disorders. In addition to; malnutrition, communication difficulties, epilepsy and abnormal behaviours. This was followed by the calculation of the comorbidity mean.

The Kruskal Wallis test was used to determine the association of comorbidity scores with the type of CP. Significance level was set at $P<0.05$. Missing data if less than $30 \%$ were included as normal. The influence of comorbidities and $\mathrm{CP}$ severity on school attendance was assessed in a bivariate analysis. Correlations between factors predicting school attendance were the sought.

Multiple logistic regression models, adjusted for age and sex, were developed to identify factors associated with poor school attendance. Variables included in the regression models included systemic comorbidities and severity of CP. These were chosen based on biological plausibility and findings from previous studies. In addition, a no selection procedure was used to include other factors: variables significant at $p<0.2$ level, or not significant at $p>0.2$ but with an odds ratio between 0.5 and 2.0 in bivariate logistic regression were also included in the multivariate model. If 2 predictors showed a strong correlation with each other (0.7-1), then only one was included in the multivariate modelling. Age and sex were included regardless.

\section{Results}

A total of 1024 children were identified by the key informants, 343(34\%) children referred did not have CP while (388/731(53\%) were confirmed to have CP at that point in time. The mean age of the children with $\mathrm{CP}$ was 9.2 years (SD) \pm 4.0 ). There were 229 (59\%) males and 159 
(41\%) females. Carers reported seeking treatment for CP first in the hospital in $56.7 \%$.

Ambulatory children (GMFCS I-III) made up 280/388 (72\%) while GMFCS IV-V were 108(28\%) of the children with CP. Spastic CP was the most common type (271/ $388,70 \%)$, and was bilateral in $163 / 271(60 \%)$ and unilateral in $108(40 \%)$.

\section{Comorbidities}

Comorbidity distribution are shown in Table 1.

Subcategories of abnormal behaviours included; Difficulties getting along with other children 240(63\%), reduced kind \& helpful behaviour 252(67\%), hyperactivity and inattention 162(43\%) and abnormal conduct 233(62\%). Neonatal seizures 108/388(28\%) (OR 4.4, 95\% CI $2.8-7.1 ; p<0.001)$, were four times more likely in children with epilepsy. Irregular antiepileptic medications were used in 7/130(5.4\%) children while others used none.

Malnutrition was seen in $200 / 388(51 \%)$ and was associated with MACS 4-5, 62/88(70\%); (OR 2.8,95\% CI: 1.7-4.7; $p<0.001$ ), GMFCS IV-V, 83/108(77\%) (OR 4.6; CI:2.8-7.7;7 $p<0.01)$. Conversely a negative association was seen with both feeding, 161/334(48\%) (OR 0.3; CI: $0.2-0.7 ; \quad P<0.001)$ and swallowing difficulties $140 /$ 299(47\%) (OR 0.4; CI:0.2-0.7; $p<0.001$ ).

The comorbidity score showed a mean of 6.4 (SD 1.9; median 6; IQR 5,8), with the Kruskal-Wallis test showing a significant difference in the distribution of the comorbidity scores between the $\mathrm{CP}$ clinical types $\left(\left(\mathrm{X}^{2}(4)=\right.\right.$ 10.921, $\mathrm{p}<0.0275)$; Dystonic CP showed the highest number of co-morbidities; 7.4 (SD 1.8 Median 7.5, IQR 6, 9). Children with more than 5 comorbidities accounted for $65 \%$ of children and at least 1 comorbidity was seen in every child (Fig. 1 and supplementary material 1).

\section{Schooling}

All the children recruited were of school age, 115/ $388(30 \%)$ had never attended school, and 145 of the $273(53 \%)$ who started school dropped out; of the 128/388 (33\%) in mainstream school, for 124/128 (97\%) children, parents reported that the children were behind in academic performance. As at the time of recruitment, two thirds of children were not in school (260/388, 67\%).

\section{Multivariate analysis}

Of the reported bivariate predictors of school attendance only swallowing and feeding difficulties showed some correlation $(R=0.7)$ hence swallowing difficulties was deleted from the multivariate model.

Age and sex adjusted multivariate analysis is shown in, Table 2.

\section{Discussion}

This population based study on children with $\mathrm{CP}$ from Nigeria a LMIC study, suggests evidence on specific comorbidities and their negative impact on school attendance which were independent of $\mathrm{CP}$ severity.

Previous studies on $\mathrm{CP}$ in children from Nigeria and LMIC have mostly been from facility based samples rather than the community. There have recently been population-based studies from Bangladesh on prevalence and co-morbidity [24], using the same methodology and from Uganda, on prevalence only [17]. Review of these, has highlighted there is a need for further populationbased studies from other LMIC to understand cultural

Table 1 Distribution of comorbidities and other variables in an unadjusted bivariate analysis showing predictors of school attendance $(n=388)$

\begin{tabular}{|c|c|c|c|c|c|}
\hline Type of comorbidity & $\mathrm{N}(\%)$ & Crude OR & $95 \%$ & & $P$ value \\
\hline Feeding difficulties & $334(86)$ & 0.06 & 0.01 & 0.3 & $<0.0001$ \\
\hline Learning difficulties & $342(88)$ & 15.8 & 6.8 & 36.7 & $<0.0001$ \\
\hline Speech impairment & $331(85)$ & 2.6 & 1.5 & 4.7 & 0.001 \\
\hline Swallowing difficulties & $299(77)$ & 0.3 & 0.2 & 0.6 & $<0.0001$ \\
\hline $\begin{array}{l}\text { Abnormal Behaviour } \\
\text { (Total difficulties score) }\end{array}$ & $231(62)$ & 1.2 & 0.8 & 1.9 & 0.355 \\
\hline Visual acuity impairment & $209(54)$ & 6.3 & 3.9 & 10.1 & $<0.0001$ \\
\hline Communication difficulties (CFCS 4-5) & $173(45)$ & 4.8 & 2.9 & 7.8 & $<0.0001$ \\
\hline Objective perceptual visual disorders & $177(46)$ & 5.2 & 1.2 & 22.8 & 0.027 \\
\hline Epilepsy & $130(35)$ & 3.0 & 1.8 & 4.9 & $<0.0001$ \\
\hline Hearing impairment & $46(12)$ & 1.3 & 0.6 & 2.5 & 0.468 \\
\hline Malnutrition & $200(51)$ & 1.8 & 1.2 & 2.8 & 0.005 \\
\hline GMFCS IV-V & $108(28)$ & 16.1 & 6.3 & 40.8 & $<0.0001$ \\
\hline MACS 4-5 & $88(23)$ & 20.2 & 6.2 & 65.4 & $<0.0001$ \\
\hline
\end{tabular}




\section{Chart Title}

80

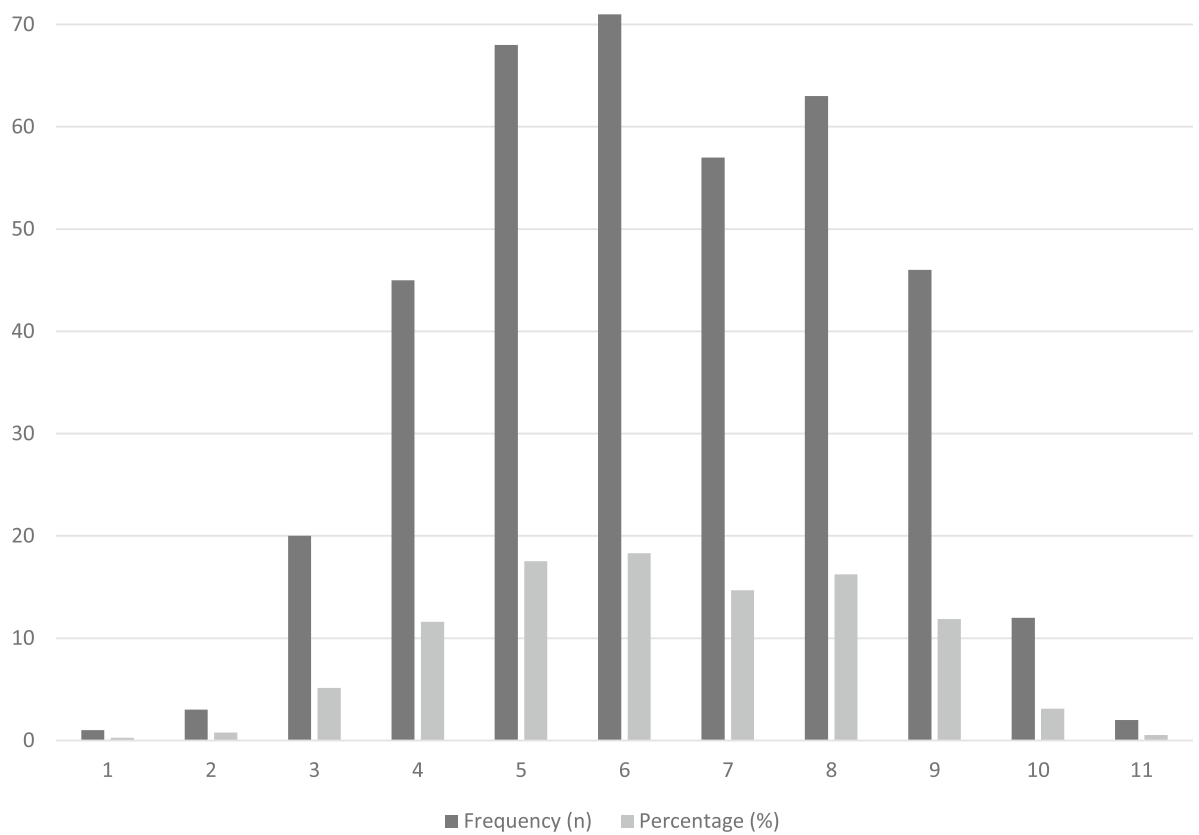

Fig. 1 Number and frequency of comorbidities in children with CP $(n=388)$

and geographic differences in the burden of comorbidities that has differed across regions [42]. .Furthermore, few studies in LMIC are available on children with $\mathrm{CP}$ from community-based studies in relation to participation in schooling and most information regarding schooling, have been based on hospital samples [5, 43].

Comparative studies have shown that the KIM can be used effectively to estimate a prevalence and identify associated comorbid conditions and predictors. For instance, a large sample of children with $\mathrm{CP}$ with physical impairment have been identified through the key informant method in Bangladesh [21, 24, 28]. However,

Table 2 Multivariate logistic regression analysis of comorbidities and other factors predicting poor school attendance in children with CP $(n=388)$

\begin{tabular}{lllll}
\hline Variables & \multicolumn{4}{l}{ Multivariate analysis } \\
\cline { 2 - 5 } Type of comorbidity & Adjusted OR & $\boldsymbol{P}$ value & $\mathbf{9 5 \%} \mathbf{C l}$ \\
\hline Age > 9 years & 0.3 & 0.001 & 0.2 & 0.6 \\
GMFCS IV-V & 6.9 & 0.002 & 2.0 & 24.0 \\
MACS 4-5 & 4.7 & 0.049 & 1.0 & 22.2 \\
Feeding difficulties & 0.1 & 0.039 & 0.02 & 0.9 \\
Learning difficulties & 10.1 & $<0.001$ & 3.6 & 28.1 \\
Visual acuity impairment & 2.8 & 0.002 & 1.5 & 5.3 \\
Epilepsy & 2.3 & 0.009 & 1.2 & 4.3 \\
\hline
\end{tabular}

the issues of stigma, difficulty with movement and poor expectations for treatment of the condition may have discouraged some parents from bringing their child for examinations [44].

All the comorbid conditions in our study occurred in higher frequency than are reported in studies from High Income Countries $[45,46]$. In the Ugandan study, two comorbidities were reported (learning disability and epilepsy) in similarly high frequencies and this was from a hospital-based study where one might expect higher level of difficulties that had resulted in referral to hospital [5]. In comparison to Bangladesh [24], the proportion with various co-morbidities was similar for some e.g. hearing impairment and higher in others e.g. visual acuity impairment. Differences seen could well be related to different screening and assessment measures as well as reflecting population differences. Our study also included other areas of difficulty which can have a significant impact such as behaviour and malnutrition.

In our population, very few of the modifiable comorbidities, such as epilepsy, were receiving treatment. Feeding and swallowing difficulties were very common but were surprisingly associated with significant reduced likelihood of malnutrition compared with severe $\mathrm{CP}$ and manual ability 4-5, which both showed an increased likelihood for malnutrition. Similar studies [47, 48], have shown an association between feeding and swallowing 
problems and malnutrition [49]. ,What may appear as a discrepancy may be as a result of the cultural feeding norms where from the age of above 4 years in these communities, feeding is communal with all the children in the household feeding from the same plate together, with the older child expected also to assist the younger children to obtain food from the plate. Children with severe $\mathrm{CP}$ and manual disability, are most unlikely to compete with their normal peers for the food. Suggesting the aetiology of malnutrition may not only be as a result of the difficulties in swallowing or chewing in these communities in children above 4 years of age.

Similar to a population based study from Uganda [5], children with dystonia had the highest mean comorbidity score. This may reflect more global insult from underlying aetiology of $\mathrm{CP}$ e.g. neonatal encephalopathy in these children. Comorbidity is associated with worse health outcomes, more complex clinical management, and increased health care costs [50]. The relationship between the number and specific comorbidity per child and mortality in children with $\mathrm{CP}$ requires further investigation across LMIC.

The importance of participation in education by children with disability including $\mathrm{CP}$ has been reiterated by several organizations [6]. We found no child attending special education school in our study. A low prevalence was seen in another Nigerian hospital-based study where only $8 \%$ attended special education schools [43]. One of the major reasons identified by the earlier study for keeping the children away from school was fear of stigma and the assumption from family members that the children were not capable of learning [43]. It is possible that parents may have noticed some of the comorbidities but did not understand or assumed that they could not be addressed. The academic expectation of children with $\mathrm{CP}$ should be tailored and agreed with parents. Understanding the link between poor school performance and comorbidity would help towards more individualised child centred approaches of care. For example, the consequence of untreated epilepsy could result in deleterious cognitive and behavioural consequences [51], both of which could be ameliorated.

Significant determinants of poor school attendance in this population independent of the severity of $\mathrm{CP}$ based on ambulation and manual disability, are: epilepsy, learning difficulties and visual acuity impairment. Some of these have proven effective interventions when indicated [49], for example, the use of antiepileptic medication in some children and the use of spectacles in children with refractive errors and/or accommodative dysfunction which are known to be beneficial $[52,53]$. Interventions may improve the quality of life, school participation, performance and favourable competition with their peers [54]. Apart from environmental and social interventions which addresses non-ambulation and manual ability, interventions to ameliorate comorbidities in children with $\mathrm{CP}$ towards improvement in schooling should be considered. Focus on the development of special education schools and complex facilities to improve capacity for clinical care, habilitation and education of children with more severe $\mathrm{CP}$ may be beneficial.

Children older than 9 years were seen to have a reduced likelihood of poor school attendance. There may be a link between mortality of children with $\mathrm{CP}$ and different age groups as well as between mortality and the development of adaptations in children with CP. These require further investigations in the implication for school attendance. A similar protective finding of significance was feeding difficulty; These was seen maybe because of the ongoing school feeding programme where parents who are aware their children's malnourished state, but do not understand the cause of the malnutrition send their children to school to participate in the school feeding programme. More investigations would clarify reasons why this is seen.

\section{Limitations of the study}

Recruitment using key informant methodology is not as rigorous as door to door population surveys but is more practical and cost effective and has been used for large and well analysed studies of CP in Bangladesh [21, 24]. Our KIM methodology has been based on the Bangladesh model however, it may have missed children resulting in selection bias. For instance, it may have been that children with more severe and stigmatising $\mathrm{CP}$ were not brought thus possibly underestimating the degree of co-morbidity in this population and hence the public health significance. Identification of comorbidities in some areas relied on parental report with possible recall bias however, there were additional extensive professional assessments used to determine comorbidity. Lastly, our choice of cut-off values affects the frequency of co-morbidities and also most likely their impact as predictors of the outcome variables. In spite of these limitations, the study probably reflects this country's best case scenario [10], used a well-established sampling methodology, trained personnel as interviewers, international classifications, and it represents a large sample in a LMIC population.

\section{Conclusion}

$\mathrm{CP}$ severity contributes significantly to poor school attendance, hence the social model of care in disability should continuously be strengthened. However, the majority of school-aged children with $\mathrm{CP}$ in this large population-based study in Southern Nigeria showed a high prevalence of multiple, untreated co-morbidities highlighting $\mathrm{CP}$ in this population as a multimorbid 
condition which may be contributing adversely to school attendance. Some of these co-morbidities that present as barriers are modifiable and if properly managed, may have the potential to have positive impacts on school attendance.

United Nations Sustainable goal four is for quality education and over half of the children who are not enrolled in school globally are in sub Saharan Africa and Nigeria is by far the largest country in sub Saharan Africa. The sustainable goals emphasise the principle of not leaving anyone behind (universal coverage) and this study highlights that comorbidity is likely to be a major impediment to school attendance for children with $\mathrm{CP}$ in low and middle income countries which requires urgent attention.

\section{Abbreviations}

CP: Cerebral palsy; GMFCS: Gross motor function classification scale; MACS: Manual ability classification scale; CFCS: Communication function classification scale; KIM: Key informant methodology; LMIC: Lower middle income country

\section{Supplementary Information}

The online version contains supplementary material available at https://doi. org/10.1186/s12887-021-02637-9.

Additional file 1 Supplementary material 1. Number and frequency of comorbidities in children with CP $(n=388)$

\section{Acknowledgments}

We acknowledge all the carers of children with CP and the key informants who participated in this study. The key informants, Caroline Arthur and Totsman Daniel the field coordinators, are acknowledged.

\section{Authors' contributions}

Conception and design of the work: Richard Bowman, Roseline E Duke, Kathryn Burton Data collection: Roseline E Duke, Chima Torty, Uche Okorie, Ukam Edadi, Nnena Eneli; Data analysis and interpretation: Roseline E Duke, Min J Kim; Drafting the article: Roseline E Duke; Critical revision of the article: Kathryn Burton, Cally Tann, Richard Bowman; Final approval of the version to be published and agreement to be accountable for all aspects of the work: Roseline E Duke, Chima Torty, Uche Okorie, Min J Kim, Kathryn Burton, Richard Bowman. The author(s) read and approved the final manuscript.

\section{Funding}

The Queen Elizabeth Diamond Jubilee Trust/Common Wealth Eye Health Consortium funded the research. Grant number [LSHTM ITCRZ6814].

\section{Availability of data and materials}

The datasets used and/or analysed during the current study are available from the corresponding author on reasonable request.

\section{Declarations}

\section{Ethics approval and consent to participate}

The study was performed in accordance with the Helsinki declaration and approved by the ethics committees of Cross River State and the London School of Hygiene \& Tropical Medicine. A written information sheet was read out and informed consent was obtained from all subjects under 18, from a parent and/or legal guardian.

Children were referred for health care services as needed.

\section{Competing interests}

The authors declare that there is no conflict of interest regarding the publication of this paper.

\section{Author details}

${ }^{1}$ London School of Hygiene \& Tropical Medicine, International Centre for Eye Health, London, UK. ²Department of Ophthalmology, University of Calabar Teaching Hospital, Calabar Children's Eye Centre, Calabar, Cross River State, Nigeria. ${ }^{3}$ Department of Paediatrics, Neurology Unit, University of Calabar Teaching Hospital, Calabar, Nigeria. ${ }^{4}$ Department of Physiotherapy, University of Calabar Teaching Hospital, Calabar, Nigeria. ${ }^{5}$ Primary Health Care Development Agency, Calabar, Cross River State, Nigeria. ${ }^{6}$ Cambridgeshire Community Services, Cambridge, UK. ${ }^{7}$ Clinical Research Department, London School of Hygiene \& Tropical Medicine, London, UK.

Received: 11 January 2021 Accepted: 25 March 2021

Published online: 08 April 2021

\section{References}

1. Vargus-Adams J. Health-related quality of life in childhood cerebral palsy. Arch Phys Med Rehabil. 2005;86(5):940-5. https://doi.org/10.1016/j.apmr.2 004.10.036.

2. Peter Rosenbaum NP, Leviton A, Goldstein M, Bax M. The Definition and Classification of Cerebral Palsy. Dev Med Child Neurol. 2007:49(Suppl. 109): 108-14.

3. Vani JW Said M KP: The PedsQL in pediatric cerebral palsy: reliability, validity, and sensitivity of the Generic Core Scales and Cerebral Palsy Module. Developmental Medicine \& Child Neurology 2006;48:442-449 2006, 48:442449.

4. Shevell MI, Dagenais L, Hall N, Consortium R. Comorbidities in cerebral palsy and their relationship to neurologic subtype and GMFCS level. Neurology. 2009:72(24):2090-6. https://doi.org/10.1212/WNL.0b013e3181aa537b.

5. Kakooza-Mwesige A, Forssberg H, Eliasson A-C, Tumwine JK. Cerebral palsy in children in Kampala, Uganda: clinical subtypes, motor function and comorbidities. BMC Res Notes. 2015;8(1):166. https://doi.org/10.1186/s13104-01 5-1125-9.

6. Chataika T, McKenzie JA, Swart E, Lyner-Cleophas M. Access to education in Africa: responding to the United Nations convention on the rights of persons with disabilities. Disability Society. 2012;27(3):385-98. https://doi. org/10.1080/09687599.2012.654989.

7. Aron L, Loprest P. Disability and the education system. Futur Child. 2012; 22(1):97-122. https://doi.org/10.1353/foc.2012.0007.

8. Watson SF. Barriers to inclusive education in Ireland: the case for pupils with a diagnosis of intellectual and/or pervasive developmental disabilities. $\mathrm{Br}$ J Learn Disabil. 2009;37(4):277-84. https://doi.org/10.1111/j.1468-3156.2009. 00583.x.

9. Rosenbaum P, Stewart D. The world health organization international classification of functioning, disability, and health: a model to guide clinical thinking, practice and research in the field of cerebral palsy. Semin Pediatr Neurol. 2004;11(1):5-10. https://doi.org/10.1016/j.spen.2004.01.002.

10. Bank W. NIGERIA-socio economic assessment. In. Edited by (AFTP3) AP. Washington, DC: The World Bank; 2011.

11. Nigeria Digest of Education Statistics.

12. Global Nutrition report: Nigeria [https://globalnutritionreport.org/resources/ nutrition-profiles/africa/western-africa/nigeria/].

13. Duke R TC, Nwachukwu K, Ameh S, Kim N, Eneli N, Onyedikachi A, Aghaji A, Burton K, Dyet L, Bowman R: Clinical features and aetiology of cerebral palsy in children from Cross River state, Nigeria. Arch Dis Child 2020, 0:1-6, 105, 1, DOI: https://doi.org/10.1136/archdischild-2019-317953.

14. Duke R NK, Torty C, Okorie U, Kim j M, Burton K, Gilbert C, Bowman R: visual impairment and perceptual visual disorders in children with cerebral palsy in Nigeria. BJO (http://bjo.bmj.com/cgi/content/full/bjophthalmol-2020-31 7768 .

15. Duke REK, Burton K, MacLeoad D, Dutton GN, Gilbert C, Bowman R. The effect of visual support strategies on the quality of life of children with cerebral palsy and cerebral visual impairment/ perceptual visual dysfunction in Nigeria: study protocol for a randomized controlled trial. Trials. 2019;20(1): 417. https://doi.org/10.1186/s13063-019-3527-9.

16. Ndem Ayara UE. Enang Udah: the universalization of basic education in Nigeria: the Cross River state experience. Wudpecker J Public Administration. 2013;1(1):007-19.

17. Kakooza-Mwesige A, Andrews C, Peterson S, Wabwire Mangen F, Eliasson AC, Forssberg H. Prevalence of cerebral palsy in Uganda: a populationbased study. Lancet Glob Health. 2017:5(12):e1275-82. https://doi.org/10.101 6/S2214-109X(17)30374-1. 
18. Adamu Sa'idu Adamu UAS. Garba Dayyabu Gwarzo, Raymond O Belonwu: nutritional status in cerebral palsy: a cross-sectional comparative survey of children in Kano, Nigeria. Nigerian Post Graduate Med J. 2018;25(3):156-60. https://doi.org/10.4103/npmj.npmj_67_18.

19. Mona P, Gajre VD, Yeradkar R, Adhikari A. Study of visual perception problems in children with learning disability. Indian J Basic Applied Medical Res. 2015;4(3):492-7.

20. National Malaria Elimination Programme (NMEP) NPCN, National Bureau of Statistics (NBS), and ICF International.: Nigeria Malaria Indicator. In: Demographic and Health Survey. Edited by Survey NMI. Abuja, Nigeria, and Rockville, Maryland, USA: NMEP, NPopC, and ICF International. ; 2015.

21. Nesbitt RCMS, Kuper H, Muhit M, Murthy GV. Predictors of referral uptake in children with disabilities in Bangladesh - exploring barriers as a first step to improving referral provision. Disabil Rehabil. 2011;34(13):1089-95. https:// doi.org/10.3109/09638288.2011.634943.

22. Sue Mackey GVSM, Mohammad A. Muhit, Johurul J. Islam, and Allen Foster: validation of the key informant method to IdentifyChildren with disabilities: methods and results from a pilot study in Bangladesh. J Trop Pediatr. 2012; 58(4):269-74. https://doi.org/10.1093/tropej/fmr094.

23. Muhit MA, Shah SP, Gilbert CE, Hartley SD, Foster A. The key informant method: a novel means of ascertaining blind children in Bangladesh. Br J Ophthalmol. 2007;91(8):995-9. https://doi.org/10.113 6/bjo.2006.108027.

24. Khandaker G, Muhit M, Karim T, Smithers-Sheedy H, Novak I, Jones C, et al. Epidemiology of cerebral palsy in Bangladesh: a population-based surveillance study. Developmental Medicine \& Child Neurology. 2018.

25. Murthy GV, Mactaggart I, Mohammad M, Islam J, Noe C, Khan Al, et al. Assessing the prevalence of sensory and motor impairments in childhood in Bangladesh using key informants. Arch Dis Child. 2014;99(12):1103-8. https://doi.org/10.1136/archdischild-2014-305937.

26. Rosenbaum PPN, Leviton A, Goldstein M, Bax M, Damiano D, Dan B, et al. A report: the definition and classification of cerebral palsy April 2006. Dev Med Child Neurol Suppl. 2007;109:8-14.

27. Palisano R, Rosenbaum P, Walter S, Russel D, Wood E, Galuppi B. Development and reliability of a system to classify gross motor function in chldren with cerebral palsy. Dev Med Child Neurol. 1997;39:214-23.

28. Khandaker G, Smithers-Sheedy H, Islam J, Alam M, Jung J, Novak I, et al. Bangladesh cerebral palsy register (BCPR): a pilot study to develop a national cerebral palsy (CP) register with surveillance of children for CP. BMC Neurol. 2015;15(1):173. https://doi.org/10.1186/s12883-015-0427-9.

29. Francesca Bertuzzi JGO, Porta MR, Paliaga GP, Miglior S. Sensitivity and specificity of a visual acuity screening protocol performed with the Lea symbols 15-line folding distance chart in preschool children. Acta Ophthalmol Scand. 2006;84(6):807-11. https://doi.org/10.1111/j.1600-0420.2 006.00668.x

30. Scruggs TE, Mastropieri MA. On babies and bathwater: addressing the problems of identification of learning disabilities. Learn Disabil Q. 2002;25(3): 155-68. https://doi.org/10.2307/1511299.

31. Thomas KGAU, Shekhar PS. Clinical practice guidelines for assessment and management of intellectual disability. Indian J Psychiatry. 2019;61(2):194210.

32. Virella D, Pennington L, Andersen GL. Andrada MdG, Greitane a, Himmelmann K, Prasauskiene a, Rackauskaite G, De La Cruz J, Colver a et al: classification systems of communication for use in epidemiological surveillance of children with cerebral palsy. Developmental Medicine \& Child Neurology. 2016;58(3):285-91. https:// doi.org/10.1111/dmcn.12866.

33. Strand EA, McCauley RJ: Differential Diagnosis of Severe Speech Impairment in Young Children.

34. Sander JSS. Incidence and prevalence studies in epilepsy and their methodological problems: a review. J Neurol Neurosurg Psychiatry. 1987; 50(7):829-39. https://doi.org/10.1136/jnnp.50.7.829.

35. Westergren ALC, Axelsson C, Ulander K. Prevalence of eating difficulties and malnutrition among persons within hospital care and special accommodations. J Nutr Health Aging. 2008;12(1):39-43. https://doi.org/10.1 007/BF02982162.

36. Gunel KMMA. T, Livanelioglu a: relationship among the manual ability classification system (MACS), the gross motor function classification system (GMFCS), and the functional status (WeeFIM) in children with spastic cerebral palsy. Eur J Pediatr. 2009;168(4):477-85. https://doi.org/10.1007/ s00431-008-0775-1.
37. Nikhat Hoosen ELD, de Vries PJ, Shung-King M. The Strengths and Difficulties Questionnaire (SDQ) in Africa: a scoping review of its application and validation. Child Adolesc Psychiatry Ment Health. 2018;12:6.

38. Van der Meer M, Dixon A, Rose D. Parent and child agreement on reports of problem behaviour obtained from a screening questionnaire, the SDQ. European child \& adolescent psychiatry. 2008;17(8):491-7. https://doi.org/1 0.1007/s00787-008-0691-y.

39. RS SJ. A health professional's guide to using growth charts. Paediatr Child Health. 2004;9:3.

40. Kuczmarski R.J OCL, Grummer-Strawn L.M, Flegal K.M, Guo S.S, Wei R CDC growth charts: United States. Adv Data 2000, 314:1-27.

41. Organization $\mathbf{W H}$, Unicef: $\mathbf{W H O}$ child growth standards and the identification of severe acute malnutrition in infants and children: joint statement by the World Health Organization and the United Nations Children's fund. 2009.

42. Andrews C, Kakooza-Mwesige A, Elisson A-C, Forssberg H. Important report on cerebral palsy in Bangladesh: but different findings compared with other countries need further exploration. Developmental Medicine \&amp. Child Neurology. 2019;61(5):511-2.

43. Lagunju IOA, Famosaya A. Cerebral palsy in Nigerian children: profile and impact on educational opportunities. DMCN. 2016;58:55.

44. Green SE. "What do you mean 'what's wrong with her?"': Stigma and the lives of families of children with disabilities. Soc Sci Med. 2003;57(8):136174. https://doi.org/10.1016/S0277-9536(02)00511-7.

45. Wichers MJ, Odding E, Stam H, van Nieuwenhuizen O. Clinical presentation, associated disorders and aetiological moments in cerebral palsy: a Dutch population-based study. Disabil Rehabil. 2005;27(10):583-9. https://doi.org/1 0.1080/09638280400018445.

46. Michael I, Shevell LD. Nicholas Hall, and on behalf of the REPACQ Consortium: comorbidities in cerebral palsy and their relationship to neurologic subtype and GMFCS level. Neurology. 2009;72(24):2090-6.

47. Gangil APA, Aneja S, Ahuja B, Anand VK. Feeding problems in children with cerebral palsy. Indian Pediatr. 2001;38(3):839-46.

48. JC A: Feeding children with cerebral palsy and swallowing difficulties. Eur J Clin Nutr 2013, 67:S9-S12, S2, DOl: https://doi.org/10.1038/ejcn.2013.224.

49. Polack S, Adams M, O'banion D, Baltussen M, Asante S, Kerac M, et al. Children with cerebral palsy in Ghana: malnutrition, feeding challenges, and caregiver quality of life. Dev Med Child Neurol. 2018;60(9):914-21. https:// doi.org/10.1111/dmen.13797.

50. Valderas JM, Starfield B, Sibbald B, Salisbury C, Roland M. Defining comorbidity: implications for understanding health and health services. Ann Fam Med. 2009;7(4):357-63. https://doi.org/10.1370/afm.983.

51. Aldenkamp AP, Weber B, Overweg-Plandsoen WC, Reijs R, van Mil S. Educational underachievement in children with epilepsy: a model to predict the effects of epilepsy on educational achievement. J Child Neurol. 2005; 20(3):175-80. https://doi.org/10.1177/08830738050200030101.

52. MJF SKJ. Spectacle intervention in children with cerebral palsy (CP) and accommodative dysfunction. Invest Ophthalmol Vis Sci. 2004;45:13.

53. Aneja SAB, Taluja V, Bhatia VK. Epilepsy in children with cerebral palsy. Indian J Pediatr. 2001;68(2):111-5. https://doi.org/10.1007/BF02722024.

54. Tessier DW, Hefner JL, Newmeyer A. Factors related to psychosocial quality of life for children with cerebral palsy. Int J Pediatr. 2014;2014:204386.

\section{Publisher's Note}

Springer Nature remains neutral with regard to jurisdictional claims in published maps and institutional affiliations.

\section{Ready to submit your research? Choose BMC and benefit from:}

- fast, convenient online submission

- thorough peer review by experienced researchers in your field

- rapid publication on acceptance

- support for research data, including large and complex data types

- gold Open Access which fosters wider collaboration and increased citations

- maximum visibility for your research: over 100M website views per year

At BMC, research is always in progress.

Learn more biomedcentral.com/submissions 